\title{
Political Sophistication and Policy Reasoning: A Reconsideration
}

\author{
Paul Goren Arizona State University
}

The sophistication-interaction theory of mass policy reasoning, which posits that the strength of the relationship between abstract principles and policy preferences is conditional on political sophistication, dominates the study of public opinion. This article argues that the sophistication-interaction theory does not hold to the degree the consensus claims. Specifically, it challenges the proposition that sophistication promotes the use of domain-specific beliefs and values. Analysis of 1984, 1986, 1987, 1988, and 1990 NES data yields two compelling findings. First, a series of confirmatory factor analyses indicate that beliefs about equal opportunity, self-reliance, and limited government in the social welfare domain and about militarism and anticommunism in the foreign policy domain are structured coherently and equivalently in the minds of citizens at different levels of sophistication. Second, structural equation model results demonstrate that political sophistication does not systematically enhance the impact these principles have on policy preferences.

$\mathrm{T}$ he conventional wisdom in public opinion research holds that the ability to deduce specific policy preferences from abstract principles is conditional on political sophistication. Research shows that sophistication strengthens the relationship between liberal-conservative orientations and issue positions (Delli Carpini and Keeter 1996; Sniderman, Brody, and Tetlock 1991; Zaller 1992). However, the consensus makes the far broader claim that sophistication promotes reliance on all abstract beliefs and values. According to Zaller, "the impact of people's value predispositions always depends on whether citizens possess the contextual information needed to translate their values into support for particular policies" (1992, 25). Delli Carpini and Keeter posit that "the greater the store of information, the more often citizens will be able to connect their values with concrete matters of politics" $(1996,229)$. Luskin maintains that " $[t]$ here are many reasons to think sophistication important, but perhaps its greatest importance lies in its conditioning of the relationship between values and policy and candidate preferences, which can be expected to be tighter among the more sophisticated" $(2002,220)$.

This article examines critically whether the sophistication-interaction model of public opinion holds to the degree the consensus claims. I draw upon the work of Feldman (1988) and Hurwitz and Peffley (1987) to argue that political sophistication will neither affect the absorption of domain-specific principles from the broader political environment, nor strengthen the impact these principles have on policy preferences. My analysis of data from five National Election Study surveys yields two compelling findings. First, I demonstrate that beliefs about equal opportunity, self-reliance, and limited government in the social welfare domain and about militarism and anticommunism in the foreign policy domain are structured coherently and equivalently in the minds of citizens at different levels of sophistication. Second, I show that individuals are, for the most part, equally adept at grounding policy preferences in these principles. Simply put, all citizens hold genuine core beliefs and values and rely more or less equally on these when taking positions on many specific issues.

\section{Theoretical and Empirical Background}

The domain-specific approach to the study of public opinion posits that everyone holds and uses abstract principles

Paul Goren is Assistant Professor of Political Science, Arizona State University, Tempe, AZ 85287-3902 (paul.goren@asu.edu).

I thank Peter Bentler, Cotton Casino, Rick Herrera, Jim Jaccard, Tim Johnson, Pat Kenney, David Kimball, George Knight, Kathleen Knight, Howie Lavine, Roger Millsap, Jeff Mondak, Tom Nelson, Paul Sniderman, and the three anonymous reviewers for their comments and assistance on this project. I assume responsibility for any remaining errors.

American Journal of Political Science, Vol. 48, No. 3, July 2004, Pp. 462-478 
relevant to a given policy domain to constrain their policy preferences within that domain. These principles help people figure out what goes with what within, but not across, distinct issue areas (Feldman 1988; Hurwitz and Peffley 1987). For example, in the social welfare arena people deduce preferences from general beliefs about equality, while in the foreign policy domain attitudes toward defense issues are rooted in beliefs about militarism. Furthermore, beliefs about equality will not influence defense attitudes, nor will militarism affect social welfare preferences.

Why should everyone base his or her policy preferences on domain-specific principles? To begin with, public discourse in a policy domain is often shaped by a few general ideas. For instance, social welfare issues frequently reflect conflict between egalitarian and individualistic values, while foreign policy debates often center on how aggressive the United States should be in international affairs. Since these ideas are easy to recognize and understand, people can acquire them from the broader political environment with little effort. As Feldman states, "[i]t should not require a high degree of political sophistication for people to absorb the political norms of society when they are so ingrained in the political and social life of the nation" $(1988,418)$.

Of course, possession does not guarantee use. There are two explanations as to why sophistication should not moderate the use of domain-specific principles. First, the information processing demands of doing so are quite low. While most people do not base policy preferences on liberal-conservative beliefs and know too little about politics to hold crystalized attitudes on most social and political issues (Converse 1964), they do adhere to a limited number of core principles from which such preferences may be readily constructed. That is, people can efficiently and effectively deduce preferences from the beliefs and values they hold. This is how cognitive misers process political information. Second, citizens are more capable of principle-based reasoning than is typically recognized. People use general beliefs and values to evaluate nonpolitical aspects of their lives (i.e., work, school, faith, and so on), and hence, can readily use these to reason about political issues when the need arises.

The sophistication-interaction theory of public opinion takes a much different view of the nature of mass policy reasoning. Sophistication theories hold that people can connect values and preferences only if they already know a good deal about public affairs. Since many people lack such knowledge to begin with, large segments of the public will be unable to base issue positions on abstract principles. Thus, the sophistication-interaction approach posits that the highly informed will rely heav- ily on domain-specific principles to constrain their issue preferences and that the uninformed cannot ground their attitudes in these principles (Converse 1964; Delli Carpini and Keeter 1996; Luskin 2002; Zaller 1992).

These competing theories of mass policy reasoning are plausible, but both cannot be right. Surprisingly, little direct evidence supports either perspective. First, the seminal works in the domain-specific tradition demonstrate that general principles influence issue attitudes, but they fail to test whether sophistication moderates these relationships. It is possible that the least sophisticated third of the public fails to absorb these principles from the political environment or is unable to effectively use what they have. Whole sample estimates could easily obscure such heterogeneity. Thus, the claims of the domain-specific approach are not empirically corroborated in its leading works.

Two more recent studies address whether sophistication conditions the use of domain-specific principles. To begin with, in his comprehensive study of mass opinion change Zaller (1992) demonstrates that sophistication promotes reliance on partisan and ideological identifications, but there is little direct evidence that sophistication enhances the use of domain-specific principles. Zaller analyzes opinion change in periods where the NES surveys lack relevant value measures; therefore, he utilizes ideology as a proxy indicator. Since ideology correlates with domain-specific principles only among the sophisticated, this strategy is invalid for drawing conclusions about whether the unsophisticated use domain-specific principles (see Goren 2001, 162-63). Goren (2001) tests for sophistication effects using valid measures of domainspecific principles in three policy domains. This work shows that sophistication promotes reliance on equal opportunity and self-reliance when citizens render social welfare preferences; does not condition the use of these principles when citizens evaluate affirmative action; and promotes reliance on moral traditionalism, but not equal opportunity, when people think about gay rights. That is, a sophistication effect emerges in three of six tests, a real, if not terribly robust, finding. Furthermore, and contrary to the predictions of sophistication theory, the unsophisticated rely on these principles. Overall, these studies suggest that sophistication matters to some extent, but they do not, and cannot, go very far toward resolving which theory better explains mass policy reasoning.

The first problem lies in failing to test the assumption that the survey items measure domain-specific principles equivalently for citizens at different levels of sophistication. Conceptually, these works assume that the sophisticated and the unsophisticated hold coherently and identically structured principles. Attitude structure research 
shows that this assumption cannot be taken for granted (Converse 1964; Delli Carpini and Keeter 1996). Empirically, these works assume that measurement equivalence holds. Measurement equivalence exists when the relationships between positions on a psychological orientation and its corresponding indicators are the same in different populations. Conversely, measurement equivalence is absent when the relationships between positions on the latent orientation and the survey items differ across populations, or when one group translates a genuine orientation into meaningful survey responses while another lacks the orientation and responds randomly to the items designed to tap it (Drasgow and Kanfer 1985; Reise, Widaman, and Pugh 1993).

The second problem with the extant work is the underlying assumption that the explanatory variables are equally reliable at different levels of sophistication. The ability to draw inferences about coefficient differences across groups from standard regression estimates rests on the assumption that random measurement error contaminates the independent variables to an equally modest degree within each sample. The presence of random measurement error in two or more predictors biases all of the regression coefficients in a statistical model in unknowable ways: the biases can be upward, downward, or even directional (Achen 1983). If the reliabilities of the predictors differ across groups, regression coefficients may be biased differentially within groups. Thus, inferences based on statistical tests of group differences in the magnitudes of coefficients are uncertain. If cross-group reliability differences exist and an interaction test reveals that a regression coefficient differs significantly across the groups, it is unclear whether this reflects a genuine interaction in the population or an artificial one generated by sample bias differences. Similarly, an insignificant interaction test may indicate a lack of group differences in the population or different levels of within-sample bias. Since variables tend to be more reliable in more sophisticated samples, structural equation modeling techniques should be employed when testing for sophistication-interaction effects.

To sum up, the question of which theory better explains mass policy reasoning is unsettled. Domain specific works assume that sophistication does not affect the structure and use of core principles. Sophistication works rest on a narrow empirical base, ignore whether sophistication moderates belief structure, and ignore the potentially destructive consequences that cross-group reliability differences may have on statistical inference. Despite the empirical limits of the domain-specific work, the argument that everyone holds and uses these principles (see above) is compelling. Therefore, I predict that $\left(\mathrm{H}_{1}\right)$ domain-specific principles will be structured equiv- alently in the minds of sophisticated and unsophisticated citizens, and $\left(\mathrm{H}_{2}\right)$ the sophisticated and the unsophisticated will rely on these principles to the same degree to deduce their policy preferences.

\section{Statistical Technique}

I use structural equation modeling techniques to generate the statistical estimates for two reasons. First, the confirmatory factor analysis component of the general model can be used to test for measurement equivalence. If the factor loadings for the domain-specific principle items are statistically identical, save for sampling variation, across sophistication-stratified samples, and the model fit statistics are substantively acceptable within and comparable across the samples, measurement equivalence very likely holds. Second, the structural component of the general model estimates relationships between latent variables after accounting for random measurement error in the observed variables. This takes care of potential problems arising from cross-group reliability differences in the observed variables. ${ }^{1}$

Model fit is assessed as follows. I report the chi-square test, which tests the null hypothesis that the population covariation matrix for the observed variables equals the population covariance matrix implied by the hypothesized model. Given the limits of this test (see Bollen 1989, 266), I report three additional fit indices that describe how well the model fits the data. These are the $\chi^{2} /$ degrees of freedom ratio, in which values of five or less indicate acceptable fit (Wheaton et al. 1977), and the adjusted goodness-of-fit index (AGFI) and the comparative fit index (CFI), where values of .90 or higher reflect good fit (Hu and Bentler 1995).

\section{The Social Welfare Domain}

\section{Data and Model}

The first set of analyses focuses on the issue of social welfare spending using data from the 1984, 1986, and 1990 NES surveys. ${ }^{2}$ Social welfare spending is one of the most important and enduring issues on the American

\footnotetext{
${ }^{1}$ In the samples used here the principle items are more reliable at higher levels of sophistication (see the Cronbach $\alpha$ estimates in the measurement model tables below), which suggests that the attitude reports of the politically aware are more crystalized than those of the unaware (cf. Chong, McClosky, and Zaller 1983).

${ }^{2}$ All models are estimated via maximum likelihood using the EQS program. ML estimation assumes that the observed variables are continuous and multivariate normally distributed. When these assumptions are violated, chi-square tests and standard errors may
} 
political agenda, and it has received extensive attention in prior work on domain-specific reasoning (Feldman 1988; Goren 2001; Kinder and Sanders 1996). The dependent variables are latent attitudes toward government spending on social programs that benefit (1) the needy and (2) the elderly. In 1984 needy programs include "food stamps," "government jobs for the unemployed," and "assistance to blacks," while elderly programs include "Medicare" and "Social Security." The 1986 and 1990 measures of each latent variable are similar. ${ }^{4}$ Each factor is scaled so higher scores reflect prospending sentiment.

Equal opportunity, self-reliance, and limited government represent the key principles in the social welfare domain (Kinder and Sanders 1996). Equal opportunity reflects the idea that society should ensure that everyone has the same chance to get ahead in life (available all years). Strong egalitarians should favor more spending than weak egalitarians. Self-reliance is the belief that hard work leads to economic success (available in 1984 and 1986). Limited government indicates whether people favor a weak or strong federal government in domestic affairs (available in 1990). Support for individualistic values should be associated with a preference to cut spending. Party identification and ideology serve as control variables: Democrats and liberals should favor more spending than Republicans and conservatives, respectively. All explanatory variables are scaled so higher values reflect more left-wing responses; each should positively affect spending preferences. Finally, the models are estimated at three levels of sophistication, which I measure using political knowledge scales (see Appendix A).

\section{Statistical and Substantive Results}

The first hypothesis maintains that each domain-specific principle is structured equivalently in the belief systems of citizens at different levels of sophistication. It will be confirmed if the factor loadings for each principle are statistically indistinguishable and the model fit statistics

be biased (Bollen 1989). To deal with this I report Satorra-Bentler (i.e., robust) $\chi^{2}$ s and robust standard errors, which are more accurate than the uncorrected ML statistics (Chou and Bentler 1995; Curran, West, and Finch 1997).

${ }^{3}$ Needy and elderly programs are treated as separate dependent variables for two reasons. Conceptually, the elderly elicit more sympathy than people on welfare, blacks, and so on. Empirically, confirmatory factor analysis reveals that a two-factor solution in which the needy items load on one factor and the elderly items load on a second fits the data quite well across sophistication-stratified samples (see Appendix B).

${ }^{4}$ Question wording and missing data information for all items appears in Appendix A. are reasonable and substantively comparable across the groups. To illustrate for 1984, Table 1 shows the loadings for the second and third equal opportunity items are as follows: $\lambda_{2}^{\text {low }}=3.33, \lambda_{2}^{\text {med }}=2.67, \lambda_{2}^{\text {high }}=4.27$, and $\lambda_{3}^{\text {low }}=2.53, \lambda_{3}^{\text {med }}=2.43, \lambda_{3}^{\text {high }}=2.05$ ( $\lambda_{1}$ equals 1.00 to scale the factor). ${ }^{5}$ Are these loadings statistically comparable across the groups? This can be determined using the Lagrange multiplier test, which assesses the statistical effect adding free parameters has on a restricted model. In the restricted model the factor loadings are constrained to be equal across the samples (i.e., $\lambda_{2}^{\text {low }}=\lambda_{2}^{\text {med }}=\lambda_{2}^{\text {high }}$ and $\left.\lambda_{3}^{\text {low }}=\lambda_{3}^{\text {med }}=\lambda_{3}^{\text {high }}\right)$. The LM test can be interpreted as the approximate increase in the model $\chi^{2}$ that results when all of the equality constraints are freed (degrees of freedom equals the number of constraints). A statistically insignificant LM test indicates that the constraints do not harm model fit, and thus, supports the inference that measurement equivalence holds (Bentler 1995, 126-28, 219-21). In short, an insignificant LM will support the conclusion that equal opportunity is structured the same way and to the same degree in the minds of individuals at different levels of awareness.

To return to the data at hand, Table 1 reveals that measurement equivalence holds generally, though not completely, for the domain-specific principles. First, the LM test for equal opportunity is statistically insignificant $\left(\chi_{4}^{2}=6.22, \mathrm{p}=.18\right)$, which means that model fit is not degraded when the loadings are constrained to be equal across the samples. In contrast, the LM test for self-reliance is statistically significant $\left(\chi_{6}^{2}=19.63, \mathrm{p}<\right.$ .01 ), which shows that the loadings are not statistically equivalent across the samples (the loadings are somewhat

${ }^{5}$ I use only three of the six equality items on the NES surveys for the following reasons. Americans equate equality with ensuring that people have the same opportunities to get ahead in life rather than having equal abilities or experiencing equal outcomes (Feldman and Zaller 1992). In terms of face validity, the items I employ (see Table 1 and Appendix A) more directly tap beliefs about equal opportunity than the items I exclude, which mention pushing equal rights (which alludes to civil rights for African Americans), worrying less about how equal people are, and if it is a problem that some people have more of a chance in life than others (the latter two seem to reference innate differences in ability). I ran a series of factor analyses on the full equality battery and found that the items I use load on one factor while the others load on a second (factor correlations are modest). Clearly, these are separate dimensions of equality, only one of which taps equal opportunity. Furthermore, in a parallel set of analyses, Sears, Henry, and Kosterman (2001, 97, $101,105)$ find (1) comparable measurement model results; (2) that the nonopportunity items correlate with measures of biological and symbolic racism; and (3) that the equal opportunity items do not correlate with the racism measures. Thus, the items I use posses discriminant validity whereas the excluded items do not. Finally, note that I use four of the six available self-reliance items because my attempts to fit a model to all six yielded a poor statistical fit. All of these analyses are available from the author upon request. 
TABLE 11984 Confirmatory Factor Analysis Models for Social Welfare Principles by Level of Sophistication, Unstandardized Estimates

\begin{tabular}{lrrr}
\hline & Low & Medium & High \\
\hline Factor Loadings: & & & \\
$\quad \xi_{1}$ Equal opportunity (five-point scale) & & & \\
$\lambda_{1}$ Make sure everyone has equal opportunity to succeed & 1.00 & 1.00 & 1.00 \\
$\lambda_{2}$ Problem in country don't give everyone equal chance & 3.33 & 2.67 & 4.27 \\
$\quad \lambda_{3}$ If people treated more equally have fewer problems & 2.53 & 2.43 & 2.05 \\
Cronbach's $\alpha$ & .54 & .56 & .59 \\
$\xi_{2}$ Self-reliance (five-point scale) & & & \\
$\lambda_{4}$ People who don't get ahead should not blame system & 1.00 & 1.00 & 1.00 \\
$\lambda_{5}$ Hard work offers little guarantee of success & 1.15 & 1.18 & 0.78 \\
$\lambda_{6}$ If people work hard almost always get what want & 2.07 & 2.00 & 1.14 \\
$\quad \lambda_{7}$ Person work hard has good chance of succeeding & 1.35 & 1.54 & 0.87 \\
Cronbach's $\alpha$ & .54 & .61 & .70 \\
Factor Correlation: & .10 & .19 & .66 \\
Model Fit: & & & \\
Robust $\chi^{2}$ & $56.16^{* *}$ & $74.09^{* *}$ & $53.19^{* *}$ \\
Degrees of freedom & 13 & 13 & 13 \\
Robust $\chi^{2} /$ degrees of freedom & 4.32 & 5.70 & 4.09 \\
AGFI & .95 & .93 & .93 \\
Robust CFI & .88 & .88 & .95 \\
Number of cases & 642 & 634 & 548 \\
\hline
\end{tabular}

** $\mathrm{p}<.01$.

Notes: Latent and observed variables are coded so higher scores reflect more left wing sentiment; therefore, each $\lambda_{i}$ should be positive. All factor loadings significant at $\mathrm{p}<.01$. The metric of each factor is defined by fixing the loading for the first item to 1.00 . LM test of equal loadings for equal opportunity: $\chi_{4}^{2}=6.22, \mathrm{p}=$ .18. LM test of equal loadings for self-reliance: $\chi_{6}^{2}=19.63, \mathrm{p}<.01$.

weaker among the high sophistication group versus the medium/low groups). Lastly, model fit is adequate within each sample and differs marginally across the samples. The $\chi^{2} /$ degrees of freedom ratios are all around the 5.00 cut point, and the AGFI and the CFI approach or surpass the .90 threshold of good fit. Overall, it appears that beliefs about equal opportunity are structured identically and beliefs about self-reliance are structured similarly across levels of sophistication.

The second hypothesis predicts that people rely on these principles to the same degree to construct their spending preferences. If the domain-specific hypothesis is right, then the $\gamma_{1}$ (equal opportunity) and $\gamma_{2}$ (selfreliance) coefficients should be positive and statistically significant in each group and statistically indistinguishable across the groups. If the sophistication-interaction model is right, then $\gamma_{1}$ and $\gamma_{2}$ should be positive and larger in higher groups $\left(\gamma_{1}^{\text {high }}>\gamma_{1}^{\text {med }}>\gamma_{1}^{\text {low }}\right.$ and $\gamma_{2}^{\text {high }}>$ $\gamma_{2}^{\text {med }}>\gamma_{2}^{\text {low }}$, significant in the high group and insignificant in the low group, and the differences in the mag- nitudes of $\gamma_{\mathrm{i}}$ should be statistically significant. LM tests are used to determine if constraining the coefficients to be equal $\left(\gamma_{1}^{\text {low }}=\gamma_{1}^{\text {med }}=\gamma_{1}^{\text {high }}\right.$ and then $\left.\gamma_{2}^{\text {low }}=\gamma_{2}^{\text {med }}=\gamma_{2}^{\text {high }}\right)$ leads to a statistically significant increase in the model $\chi^{2}$ (degrees of freedom equals the number of constraints). Insignificant LM tests will support the conclusion that sophistication does not condition the use of these two principles. ${ }^{6}$

Table 2 reports the $\gamma$ coefficients, robust standard errors, model-fit statistics, and LM tests for the 1984 needy and elderly spending models. The results clearly support the domain-specific theory of mass policy reasoning. First, in both sets of models the equal opportunity variable is correctly signed and statistically significant at each level of sophistication, and its effect does not differ significantly across the samples (needy $\chi_{2}^{2}=0.99$, $\mathrm{p}=.61$; elderly $\chi_{2}^{2}=0.38, \mathrm{p}=.83$ ). Strong egalitarians

${ }^{6}$ Space limits preclude inclusion of the measurement model estimates that accompany the structural estimates. These are available from the author upon request. 
TABLE 21984 Structural Equation Models for Social Welfare Spending Preferences by Level of Sophistication, Unstandardized Estimates

\begin{tabular}{|c|c|c|c|c|c|c|}
\hline & \multicolumn{3}{|c|}{ Programs for the Needy } & \multicolumn{3}{|c|}{ Programs for the Elderly } \\
\hline & Low & Medium & High & Low & Medium & High \\
\hline \multicolumn{7}{|l|}{ Structural Coefficients: } \\
\hline$\gamma_{1}$ Equal opportunity & $\begin{array}{c}0.678^{* *} \\
(.157)\end{array}$ & $\begin{array}{c}0.671^{* *} \\
(.137)\end{array}$ & $\begin{array}{c}0.930^{* *} \\
(.259)\end{array}$ & $\begin{array}{l}0.262^{* *} \\
(.105)\end{array}$ & $\begin{array}{c}0.352^{* *} \\
(.095)\end{array}$ & $\begin{array}{c}0.312^{*} \\
(.176)\end{array}$ \\
\hline$\gamma_{2}$ Self-reliance & $\begin{array}{r}-0.067 \\
(.092)\end{array}$ & $\begin{array}{r}-0.051 \\
(.057)\end{array}$ & $\begin{array}{r}-0.074 \\
(.056)\end{array}$ & $\begin{array}{l}0.110 \\
(.076)\end{array}$ & $\begin{array}{l}0.034 \\
(.049)\end{array}$ & $\begin{array}{r}-0.037 \\
(.053)\end{array}$ \\
\hline$\gamma_{3}$ Party identification & $\begin{array}{c}0.097^{* *} \\
(.027)\end{array}$ & $\begin{array}{c}0.064^{* *} \\
(.019)\end{array}$ & $\begin{array}{c}0.071^{* *} \\
(.029)\end{array}$ & $\begin{array}{c}0.060^{* *} \\
(.021)\end{array}$ & $\begin{array}{c}0.039^{* *} \\
(.016)\end{array}$ & $\begin{array}{c}0.106^{* *} \\
(.027)\end{array}$ \\
\hline$\gamma_{4}$ Ideology & $\begin{array}{r}-0.017 \\
(.034)\end{array}$ & $\begin{array}{l}0.001 \\
(.030)\end{array}$ & $\begin{array}{c}0.083^{*} \\
(.040)\end{array}$ & $\begin{array}{r}-0.010 \\
(.026)\end{array}$ & $\begin{array}{r}-0.019 \\
\quad(.027)\end{array}$ & $\begin{array}{l}0.008 \\
(.039)\end{array}$ \\
\hline \multicolumn{7}{|l|}{ Model Fit: } \\
\hline Robust $\chi^{2}$ & $96.74^{* *}$ & $122.19^{* *}$ & $154.68^{* *}$ & $94.55^{* *}$ & $101.51^{* *}$ & $114.18^{* *}$ \\
\hline Degrees of freedom & 56 & 56 & 56 & 45 & 45 & 45 \\
\hline Robust $\chi^{2} /$ d.f. & 1.73 & 2.18 & 2.76 & 2.10 & 2.26 & 2.54 \\
\hline AGFI & .95 & .95 & .92 & .95 & .95 & .93 \\
\hline Robust CFI & .95 & .95 & .96 & .93 & .95 & .97 \\
\hline Number of cases & 489 & 528 & 499 & 519 & 551 & 528 \\
\hline
\end{tabular}

${ }^{*} \mathrm{p}<.05 ;{ }^{* *} \mathrm{p}<.01$.

Notes: Higher values on the variables reflect more left wing sentiment; therefore, each $\gamma_{i}$ should be positive. CFA estimates omitted for clarity.

For the needy models:

The dependent variable is latent support for spending on social programs that benefit the needy (three-point scale). Robust standard errors are in parentheses. LM test of equal $\gamma_{1}: \chi_{2}^{2}=0.99, p=.61$.

For the elderly models:

The dependent variable is latent support for spending on social programs that benefit the elderly (three-point scale). Robust standard errors are in parentheses. LM test of equal $\gamma_{1}: \chi_{2}^{2}=0.38, p=.83$.

consistently favor more social spending than weak egalitarians. Second, self-reliance has no effect, surprisingly, on spending attitudes in any sample. Third, party identification influences preferences as predicted in every sample, ideology matters only for the sophisticated in the needy models, and model fit is excellent in each sample. In sum, political sophistication does not seem to moderate policy reasoning about social spending, at least in 1984.

For the 1986 data, the measurement model and structural equation estimates are presented in Tables 3 and 4, respectively. Table 3 shows that measurement equivalence holds for both equal opportunity and self-reliance. More specifically, the factor loadings are statistically comparable across the sophistication-stratified samples (equal opportunity $\chi_{4}^{2}=4.83, \mathrm{p}=.31$; self-reliance $\chi_{6}^{2}=5.43$, $\mathrm{p}=.49$ ), and the $\chi^{2} /$ degrees of freedom ratios and the AGFI and CFI indices reveal that model fit is good within and similar across all three samples. Thus, it appears that the process of translating beliefs about equal opportunity and self-reliance into survey responses is the same for ev- eryone regardless of how much or little they know about public affairs.

Next, the structural equation estimates in Table 4, while somewhat mixed, furnish more support for the domain-specific theory than for the sophisticationinteraction approach. First, in both the needy and the elderly models the equal opportunity variable is always positive, it is significant in five of the six samples, and its effect does not vary across the samples (needy $\chi_{2}^{2}=1.83$, $\mathrm{p}=.40$; elderly $\chi_{2}^{2}=0.27, \mathrm{p}=.87$ ). Strong egalitarians consistently favor more spending than weak egalitarians. Second, in the needy models the magnitude of the selfreliance coefficient increases monotonically as a function of sophistication, and it attains significance in the medium and high samples. Among these groups, a weaker commitment to self-reliance is associated with more support for spending on the needy. These differences, while impressive in substantive terms $\left(\gamma_{2}^{\text {low }}=0.087\right.$ vs. $\left.\gamma_{2}^{\text {high }}=0.274\right)$, are not statistically significant $\left(\chi_{2}^{2}=1.50, \mathrm{p}=.47\right)$. However, in the elderly models self-reliance once again has no 
TABLE 31986 Confirmatory Factor Analysis Models for Social Welfare Principles by Level of Sophistication, Unstandardized Estimates

\begin{tabular}{lrrr}
\hline & Low & Medium & High \\
\hline Factor Loadings: & & & \\
$\quad \xi_{1}$ Equal opportunity (five-point scale) & & & \\
$\lambda_{1}$ Make sure everyone has equal opportunity to succeed & 1.00 & 1.00 & 1.00 \\
$\lambda_{2}$ Problem in country don't give everyone equal chance & 2.86 & 1.81 & 2.00 \\
$\lambda_{3}$ If people treated more equally have fewer problems & 2.32 & 2.32 & 1.90 \\
Cronbach's $\alpha$ & .57 & .64 & .66 \\
$\xi_{2}$ Self-reliance (five-point scale) & & & \\
$\lambda_{4}$ People who don't get ahead should not blame system & 1.00 & 1.00 & 1.00 \\
$\lambda_{5}$ Hard work offers little guarantee of success & 0.90 & 1.05 & 1.00 \\
$\lambda_{6}$ If people work hard almost always get what want & 1.93 & 2.13 & 1.35 \\
$\quad \lambda_{7}$ Person work hard has good chance of succeeding & 1.49 & 1.46 & 1.06 \\
Cronbach's $\alpha$ & .51 & .54 & .65 \\
Factor Correlation: & -.09 & .14 & .30 \\
Model Fit: & & & \\
Robust $\chi^{2}$ & $33.24^{* *}$ & $25.34^{*}$ & $48.68^{* *}$ \\
Degrees of freedom & 13 & 13 & 13 \\
Robust $\chi^{2} /$ degrees of freedom & 2.56 & 1.95 & 3.74 \\
AGFI & .95 & .96 & .90 \\
Robust CFI & .90 & .95 & .88 \\
Number of cases & 385 & 371 & 290 \\
\hline
\end{tabular}

${ }^{*} \mathrm{p}<.05 ;{ }^{* *} \mathrm{p}<.01$.

Notes: Latent and observed variables are coded so higher scores reflect more left wing sentiment; therefore, each $\lambda_{i}$ should be positive. All factor loadings significant at $\mathrm{p}<.01$. The metric of each factor is defined by fixing the loading for the first item to 1.00. LM test of equal loadings for equal opportunity: $\chi_{4}^{2}=4.83, \mathrm{p}=$ .31. LM test of equal loadings for self-reliance: $\chi_{6}^{2}=5.43, \mathrm{p}=.49$.

effect on spending preferences. Third, party identification is correctly signed and statistically significant while ideology is insignificant in five of the six samples. Fourth, model fit is quite good across the board. Overall, the equal opportunity results for both issues strongly support the domain-specific approach, while the self-reliance effect from the needy models supports sophistication theory (but keep in mind that the differences in $\gamma_{2}$ are not statistically significant).

For the 1990 data, the confirmatory factor analysis and structural equation estimates appear in Tables 5 and 6 , respectively. The first point to note, as Table 5 reveals, is that the LM tests for both principles are statistically insignificant (equal opportunity $\chi_{4}^{2}=8.03, \mathrm{p}=.09$; limited government $\chi_{4}^{2}=3.74, \mathrm{p}=.44$ ) and that the hypothesized model fits the sample data very well within and across the groups. In other words, these principles are structured rationally and equivalently in the belief systems of citizens across the awareness spectrum.

Does political sophistication strengthen the relationship between these principles and attitudes toward social spending? The results reported in Table 6 are inconclusive. First, in the needy models equal opportunity is positive and significant in each sample, and it manifests a stronger effect in the high group versus the low/medium groups $\left(\chi_{2}^{2}=6.37, \mathrm{p}=.04\right)$. However, in the elderly models equal opportunity is positive and significantly larger in the low/high samples compared to the medium sample $\left(\chi_{2}^{2}=6.06, p=.05\right)$. Second, in the needy models all citizens rely the same amount on limited government to constrain their spending preferences $\left(\chi_{2}^{2}=0.73, \mathrm{p}=\right.$ .70). Those who want strong government favor spending more so than those who want limited government. This effect is not present in the elderly models, as the limited government variable is correctly signed and statistically significant only in the least sophisticated sample. Third, neither party identification nor ideology matter much for policy reasoning about either type of social spending. Fourth, model fit is fine within and comparable across the samples for both issues. In sum, the limited government results from the needy models buttress the domainspecific theory; the equal opportunity results in the needy 
TABLE 41986 Structural Equation Models for Social Welfare Spending Preferences by Level of Sophistication, Unstandardized Estimates

\begin{tabular}{|c|c|c|c|c|c|c|}
\hline & \multicolumn{3}{|c|}{ Programs for the Needy } & \multicolumn{3}{|c|}{ Programs for the Elderly } \\
\hline & Low & Medium & High & Low & Medium & High \\
\hline \multicolumn{7}{|l|}{ Structural Coefficients: } \\
\hline \multirow[t]{2}{*}{$\gamma_{1}$ Equal opportunity } & $0.615^{* *}$ & $0.383^{* *}$ & $0.492^{* *}$ & $0.303^{*}$ & $0.255^{* *}$ & 0.210 \\
\hline & $(.168)$ & $(.088)$ & $(.107)$ & $(.131)$ & $(.087)$ & $(.141)$ \\
\hline \multirow[t]{2}{*}{$\gamma_{2}$ Self-reliance } & 0.087 & $0.213^{* *}$ & $0.274^{* *}$ & -0.152 & 0.142 & -0.055 \\
\hline & $(.119)$ & $(.089)$ & $(.082)$ & $(.137)$ & $(.087)$ & $(.073)$ \\
\hline \multirow[t]{2}{*}{$\gamma_{3}$ Party identification } & $0.073^{*}$ & $0.093^{* *}$ & $0.067^{* *}$ & 0.022 & $0.059^{* *}$ & $0.082^{* *}$ \\
\hline & $(.032)$ & $(.021)$ & $(.026)$ & $(.023)$ & $(.021)$ & $(.034)$ \\
\hline \multirow[t]{2}{*}{$\gamma_{4}$ Ideology } & 0.014 & $0.097^{* *}$ & -0.031 & 0.014 & 0.038 & -0.031 \\
\hline & $(.044)$ & $(.040)$ & $(.055)$ & $(.035)$ & $(.037)$ & $(.060)$ \\
\hline \multicolumn{7}{|l|}{ Model Fit: } \\
\hline Robust $\chi^{2}$ & 68.15 & $78.33^{*}$ & $125.76^{* *}$ & 48.76 & $57.32^{*}$ & $83.41^{* *}$ \\
\hline Degrees of freedom & 56 & 56 & 56 & 36 & 36 & 36 \\
\hline Robust $\chi^{2} /$ d.f. & 1.22 & 1.40 & 2.25 & 1.35 & 1.59 & 2.32 \\
\hline AGFI & .94 & .94 & .88 & .95 & .95 & .90 \\
\hline Robust CFI & .98 & .97 & .93 & .97 & .96 & .95 \\
\hline Number of cases & 297 & 297 & 251 & 323 & 334 & 276 \\
\hline
\end{tabular}

${ }^{*} \mathrm{p}<.05 ;{ }^{* *} \mathrm{p}<.01$.

Notes: Higher values on the variables reflect more left wing sentiment; therefore, each $\gamma_{i}$ should be positive. CFA estimates omitted for clarity.

For the needy models:

The dependent variable is latent support for spending on social programs that benefit the needy (three-point scale). Robust standard errors are in parentheses. LM test of equal $\gamma_{1}: \chi_{2}^{2}=1.83, p=.40$. LM test of equal $\gamma_{2}: \chi_{2}^{2}=1.50$, $\mathrm{p}=.47$.

For the elderly models:

The dependent variable is latent support for spending on Social Security (three-point scale). Robust standard errors are in parentheses. LM test of equal $\gamma_{1}: \chi_{2}^{2}=0.27, \mathrm{p}=.87$.

models support the sophistication-interaction theory to some extent (although the significant $\gamma_{1}$ in the low sample and the nonmonotonic pattern of results weakens the case); and the equal opportunity effect in the elderly models supports neither theory.

\section{Summary of Social Welfare Results}

Overall, the key findings are as follows. First, the confirmatory factor-analysis models suggest that all citizens hold genuine and comparably structured beliefs about equal opportunity, self-reliance, and limited government. Measurement equivalence holds statistically in five of the six tests and substantively in all six. Second, the structural equation models imply that most people use these principles some of the time to guide their preferences on social spending, and that sophistication does not systematically condition these relationships. The domain-specific theory is supported by the findings that everyone relies on equal opportunity to the same degree in the 1984 and 1986 needy and elderly models, and on limited government in the 1990 needy models. The sophistication-interaction theory is supported by the findings that the highly aware rely more on self-reliance in the 1986 needy models and equal opportunity in the 1990 needy models (though there is some countervailing evidence in each case). Simply put, the results support domain-specific theory five times, sophistication-interaction theory twice, and neither theory once (the 1990 elderly models).

\section{The Foreign Policy Domain Data and Model}

The next set of analyses focuses on foreign policy issues using NES data from the 1988 survey and the 1987 pilot. I select foreign policy as the second domain to analyze because scholars disagree sharply over whether 
TABLE 51990 Confirmatory Factor Analysis Models for Social Welfare Principles by Level of Sophistication, Unstandardized Estimates

\begin{tabular}{lccc}
\hline & Low & Medium & High \\
\hline Factor Loadings: & & & \\
$\xi_{1}$ Equal opportunity (five-point scale) & & & \\
$\quad \lambda_{1}$ Make sure everyone has equal opportunity to succeed & 1.00 & 1.00 & 1.00 \\
$\lambda_{2}$ Problem in country don't give everyone equal chance & 1.93 & 1.89 & 1.54 \\
$\lambda_{3}$ If people treated more equally have fewer problems & 2.33 & 2.97 & 1.46 \\
Cronbach's $\alpha$ & .59 & .60 & .68 \\
$\xi_{2}$ Limited government (three-point scale) & & & \\
$\quad \lambda_{4}$ Strong government vs. free market & 1.00 & 1.00 & 1.00 \\
$\lambda_{5}$ Less government vs. more government & 1.65 & 1.07 & 1.02 \\
$\quad \lambda_{6}$ Main reason government has become bigger & 1.05 & 0.95 & 1.02 \\
Cronbach's $\alpha$ & .52 & .67 & .77 \\
Factor Correlation: & .26 & .13 & .42 \\
Model Fit: & & & \\
Robust $\chi^{2}$ & $18.07^{*}$ & $25.58^{* *}$ & 6.87 \\
Degrees of freedom & 8 & 8 & 8 \\
Robust $\chi^{2} /$ degrees of freedom & 2.26 & 3.20 & 0.86 \\
AGFI & .95 & .94 & .98 \\
Robust CFI & .93 & .94 & 1.00 \\
Number of cases & 318 & 334 & 262 \\
\hline
\end{tabular}

${ }^{*} \mathrm{p}<.05 ;{ }^{* *} \mathrm{p}<.01$.

Notes: Latent and observed variables are coded so higher scores reflect more left wing sentiment; therefore, each $\lambda_{i}$ should be positive. All factor loadings significant at $\mathrm{p}<.01$. The metric of each factor is defined by fixing the loading for the first item to 1.00. LM test of equal loadings for equal opportunity: $\chi_{4}^{2}=8.03, \mathrm{p}=$ .09. LM test of equal loadings for limited government: $\chi_{4}^{2}=3.74, \mathrm{p}=.44$.

sophistication matters in this area (Hurwitz and Peffley 1987; Zaller 1992). In addition, foreign policy issues are further removed from the lives of citizens than domestic concerns; therefore, this issue area provides a difficult test for domain-specific theory. The dependent variables in the structural models are attitudes toward (1) defense spending (available both years), (2) aid to the contras (available both years), and (3) building more nuclear weapons (available in 1987). These variables are scaled so higher scores reflect more hawkish responses.

The key domain-specific principles in the foreign policy domain are militarism and anticommunism (Hurwitz and Peffley 1990, 1987). Militarism denotes whether people believe the United States should take a flexible or tough posture in dealing with foreign adversaries. Anticommunism reflects the degree of support for U.S. efforts to contain Soviet and communist influences abroad. Both variables are scaled so higher scores reflect more hawkish responses; hence, they should positively affect the policy preference variables. Party identification serves as a control variable and is scaled so that higher values re- flect democratic affinities; it should negatively affect policy preferences. Estimates are generated at three levels of sophistication for 1988 and two for $1987 .^{7}$

\section{Statistical and Substantive Results}

Do the politically aware and the unaware conceive of militarism and anticommunism in a similar fashion? The 1988 results suggest that, for the most part, they do. Table 7 shows that the LM tests for militarism $\left(\chi_{4}^{2}=1.46\right.$, $\mathrm{p}=.83)$ and anticommunism $\left(\chi_{2}^{2}=2.37, \mathrm{p}=.31\right)$ are statistically insignificant, so we can conclude that measurement equivalence holds formally. Next, the model fit results are substantively similar, with one exception. In the low sample the $\chi^{2} /$ degrees of freedom ratio falls below the 5.00 cut-point for acceptable fit, and the AGFI and CFI values exceed the desired .90 threshold. In the medium

\footnotetext{
${ }^{7}$ Two further notes about the models. First, given the limited number of cases in the pilot study I split it into two rather than three groups. Second, ideology has little effect on the preference variables; therefore, it is excluded from the models.
} 


\section{TABLE 61990 Structural Equation Models for Social Welfare Spending Preferences} by Level of Sophistication, Unstandardized Estimates

\begin{tabular}{|c|c|c|c|c|c|c|}
\hline & \multicolumn{3}{|c|}{ Programs for the Needy } & \multicolumn{3}{|c|}{ Programs for the Elderly } \\
\hline & Low & Medium & High & Low & Medium & High \\
\hline \multicolumn{7}{|l|}{ Structural Coefficients: } \\
\hline \multirow[t]{2}{*}{$\gamma_{1}$ Equal opportunity } & $0.346^{* *}$ & $0.230^{* *}$ & $0.545^{* *}$ & $0.398^{* *}$ & 0.127 & $0.504^{* *}$ \\
\hline & $(.120)$ & $(.068)$ & $(.125)$ & $(.142)$ & $(.087)$ & $(.141)$ \\
\hline \multirow[t]{2}{*}{$\gamma_{2}$ Limited government } & $0.207^{*}$ & $0.113^{*}$ & $0.109^{* *}$ & $0.317^{*}$ & 0.107 & -0.012 \\
\hline & $(.125)$ & $(.052)$ & $(.042)$ & $(.188)$ & $(.082)$ & $(.077)$ \\
\hline \multirow[t]{2}{*}{$\gamma_{3}$ Party identification } & 0.023 & $0.043^{* *}$ & -0.003 & 0.014 & $0.061^{* *}$ & 0.048 \\
\hline & $(.015)$ & $(.016)$ & $(.017)$ & $(.018)$ & $(.023)$ & $(.035)$ \\
\hline \multirow[t]{2}{*}{$\gamma_{4}$ Ideology } & $0.052^{*}$ & 0.035 & $0.054^{*}$ & -0.011 & 0.027 & -0.100 \\
\hline & $(.027)$ & $(.024)$ & $(.029)$ & $(.037)$ & $(.038)$ & $(.062)$ \\
\hline \multicolumn{7}{|l|}{ Model Fit: } \\
\hline Robust $\chi^{2}$ & 57.84 & $118.54^{* *}$ & $84.29^{* *}$ & 23.70 & $57.40^{* *}$ & 33.04 \\
\hline Degrees of freedom & 56 & 56 & 56 & 27 & 27 & 27 \\
\hline Robust $\chi^{2} /$ d.f. & 1.03 & 2.12 & 1.51 & 0.88 & 2.13 & 1.22 \\
\hline AGFI & .94 & .91 & .92 & .96 & .93 & .95 \\
\hline Robust CFI & 1.00 & .92 & .98 & 1.00 & .94 & .99 \\
\hline Number of cases & 258 & 295 & 239 & 266 & 308 & 252 \\
\hline
\end{tabular}

${ }^{*} \mathrm{p}<.05 ;{ }^{* *} \mathrm{p}<.01$.

Notes: Higher values on the variables reflect more left wing sentiment; therefore, each $\gamma_{i}$ should be positive. CFA model estimates omitted for clarity.

For the needy models:

The dependent variable is latent support for spending on social programs that benefit the needy (three-point scale). Robust standard errors are in parentheses. LM test of equal $\gamma_{1}: \chi_{2}^{2}=6.37, p=.04$. LM test of equal $\gamma_{2}: \chi_{2}^{2}=0.73$, $\mathrm{p}=.70$.

For the elderly models:

The dependent variable is latent support for spending on Social Security (three-point scale). Robust standard errors are in parentheses. LM test of equal $\gamma_{1}: \chi_{2}^{2}=6.06, p=.05$. LM test of equal $\gamma_{2}: \chi_{2}^{2}=3.84, p=.15$.

and high samples the chi-square ratios exceed 5.00, but the AGFI and CFI values are reasonable. Overall, the weight of the evidence suggests that foreign policy beliefs are structured similarly across levels of sophistication.

Do the aware and the unaware rely on militarism and anticommunism to the same degree to construct their defense spending preferences? The estimates in Table 8 reveal that this is the case. To begin with, the militarism coefficient is positive and significant in each sample and does not differ statistically across the samples $\left(\chi_{2}^{2}=3.13\right.$, $\mathrm{p}=.21$ ). Militarists want to spend more on defense than nonmilitarists, regardless of how much or little they know about politics. Second, anticommunism does not manifest the predicted effect in any sample. Third, as expected, Democratic partisanship is inversely related to spending preferences. Fourth, the descriptive fit indices show that model fit is excellent within and differs trivially across the samples. To sum up, the domain-specific theory outperforms the sophistication-interaction theory in explaining how citizens reason about defense spending.
On the other hand, the sophistication approach does a better job accounting for mass policy reasoning on the issue of contra aid. To start with, the militarism effect increases at each level of sophistication and reaches significance in the medium/high groups. Although the effect does not differ statistically across the samples $\left(\chi_{2}^{2}=2.59\right.$, $\mathrm{p}=.27)$, the differences are impressive in substantive terms $\left(\gamma_{1}^{\text {low }}=0.086\right.$ vs. $\left.\gamma_{1}^{\text {high }}=0.450\right)$. The estimates suggest that militarism is positively associated with support for contra aid among highly and moderately sophisticated citizens and that it is unrelated to attitudes toward contra aid among the unsophisticated. Next, anticommunism again fails to consistently influence foreign policy preferences across the samples, while partisanship behaves as predicted in the two higher samples. Finally, model fit is fine within and across the samples.

Shifting attention to the 1987 models, we can see that a comparable pattern of results obtains. First, the confirmatory factor analysis models in Table 9 show that the politically aware and the unaware hold equivalently structured 
TABLE 71988 Confirmatory Factor Analysis Models for Foreign Policy Principles by Level of Sophistication, Unstandardized Estimates

\begin{tabular}{lccc}
\hline & Low & Medium & High \\
\hline Factor Loadings: & & & \\
$\xi_{1}$ Militarism (three-point scale) & & & \\
$\quad \lambda_{1}$ Better way to keep peace strong military/bargaining & 1.00 & 1.00 & 1.00 \\
$\lambda_{2}$ How important strong military for dealing w/enemies & 1.28 & 1.29 & 1.13 \\
$\quad \lambda_{3}$ U.S. maintain power even if it means brink of war & 2.02 & 1.84 & 1.75 \\
Cronbach's $\alpha$ & .54 & .64 & .68 \\
$\xi_{2}$ Anticommunism (five-point scale) & & & \\
$\quad \lambda_{4}$ Any time country goes communist a threat to U.S. & 1.00 & 1.00 & 1.00 \\
$\lambda_{5}$ U.S. do everything to prevent spread communism & 0.84 & 0.98 & 1.04 \\
Cronbach's $\alpha$ & .67 & .77 & .81 \\
Factor Correlation: & .67 & .63 & .73 \\
Model Fit: & & & \\
Robust $\chi^{2}$ & $12.35^{*}$ & $31.68^{* *}$ & $27.33^{* *}$ \\
Degrees of freedom & 4 & 4 & 4 \\
Robust $\chi^{2} /$ degrees of freedom & 3.09 & 7.92 & 6.83 \\
AGFI & .96 & .92 & .89 \\
Robust CFI & .98 & .96 & .96 \\
Number of cases & 581 & 670 & 432 \\
\hline
\end{tabular}

${ }^{*} \mathrm{p}<.05 ;{ }^{* *} \mathrm{p}<.01$.

Notes: Latent and observed variables are coded so higher scores reflect more hawkish sentiment; therefore, each $\lambda_{i}$ should be positive. All factor loadings significant at $\mathrm{p}<.01$. The metric of each factor is defined by fixing the loading for the first item to 1.00 . LM test of equal loadings for militarism: $\chi_{4}^{2}=1.46, p=.83$. LM test of equal loadings for anticommunism: $\chi_{2}^{2}=2.37, \mathrm{p}=.31$.

beliefs about militarism and anticommunism. The factor loadings are statistically indistinguishable (militarism $\chi_{2}^{2}=4.21, \mathrm{p}=.12$; anticommunism $\chi_{1}^{2}=0.50, \mathrm{p}=.48$ ), and model fit is substantively comparable in these samples. Second, Table 10 shows that for the defense-spending issue everyone relies equally on militarism $\left(\chi_{1}^{2}=0.28, \mathrm{p}=\right.$ $.60)$, and that the sophisticated alone use it to construct preferences on contra aid $\left(\gamma_{1}^{\text {low }}=0.046, p=.40\right.$ vs. $\gamma_{1}^{\text {high }}=$ $0.444, \mathrm{p}<.01$; the coefficients do not differ significantly as the LM test shows: $\chi_{1}^{2}=2.46, \mathrm{p}=.12$ ). On the issue of building more nuclear arms sophistication is irrelevant: everyone uses militarism to the same extent $\left(\chi_{1}^{2}=0.41\right.$, $\mathrm{p}=52$ ). Third, anticommunism and party identification have no effect whatsoever. Finally, model fit is uniformly excellent.

\section{Summary of Foreign Policy Results}

Overall, the foreign policy results yield some support for both theories, but the evidence comes down more in favor of the domain-specific approach. First, the four LM tests and model-fit comparisons indicate that all citizens possess genuine and similarly structured beliefs about militarism and anticommunism. Second, the structural models show that sophistication does not affect how citizens think about defense spending or nuclear arms, but that it seems to matter for contra aid. Consistent with the domain-specific approach, people rely on militarism to the same degree when deducing attitudes toward defense spending and nuclear arms. On the more arcane issue of aiding the contra rebels, only the sophisticated use militarism, as predicted by the sophistication-interaction theory (cf. Zaller 1992, 144-47). In short, the results support the domain-specific theory three times and the sophistication-interaction theory twice.

\section{Summary and Conclusions}

This article posits that the domain-specific theory of mass policy reasoning better reflects how citizens think about political issues than the sophistication-interaction theory that currently dominates the study of public opinion. I have drawn on the works of Feldman (1988) and Hurwitz 


\section{TABle 81988 Structural Equation Models for Foreign Policy Preferences by Level} of Sophistication, Unstandardized Estimates

\begin{tabular}{|c|c|c|c|c|c|c|}
\hline & \multicolumn{3}{|c|}{ Defense Spending } & \multicolumn{3}{|c|}{ Aid to Contras } \\
\hline & Low & Medium & High & Low & Medium & High \\
\hline \multicolumn{7}{|l|}{ Structural Coefficients: } \\
\hline$\gamma_{1}$ Militarism & $\begin{array}{c}2.213^{* *} \\
(.479)\end{array}$ & $\begin{array}{l}1.546^{* *} \\
(.239)\end{array}$ & $\begin{array}{l}1.253^{* *} \\
(.267)\end{array}$ & $\begin{array}{l}0.086 \\
(.156)\end{array}$ & $\begin{array}{c}0.197^{*} \\
(.099)\end{array}$ & $\begin{array}{c}0.450^{* *} \\
(.160)\end{array}$ \\
\hline$\gamma_{2}$ Anticommunism & $\begin{array}{r}-0.292^{*} \\
(.173)\end{array}$ & $\begin{array}{l}0.067 \\
(.095)\end{array}$ & $\begin{array}{l}0.133 \\
(.101)\end{array}$ & $\begin{array}{l}0.081 \\
(.066)\end{array}$ & $\begin{array}{c}0.112^{* *} \\
(.039)\end{array}$ & $\begin{array}{c}0.065 \\
(.061)\end{array}$ \\
\hline$\gamma_{3}$ Party identification & $\begin{array}{r}-0.097^{*} \\
(.042)\end{array}$ & $\begin{array}{c}-0.148^{* *} \\
(.038)\end{array}$ & $\begin{array}{c}-0.200^{* *} \\
(.055)\end{array}$ & $\begin{array}{r}-0.024 \\
(.021)\end{array}$ & $\begin{array}{c}-0.114^{* *} \\
(.017)\end{array}$ & $\begin{array}{c}-0.103^{* *} \\
(.025)\end{array}$ \\
\hline \multicolumn{7}{|l|}{ Model Fit: } \\
\hline Robust $\chi^{2}$ & $28.66^{*}$ & $46.39^{* *}$ & $52.58^{* *}$ & 20.09 & $41.96^{* *}$ & $54.88^{* *}$ \\
\hline Degrees of freedom & 15 & 15 & 15 & 15 & 15 & 15 \\
\hline Robust $\chi^{2} /$ d.f. & 1.91 & 3.09 & 3.51 & 1.34 & 2.80 & 3.66 \\
\hline AGFI & .96 & .95 & .92 & .98 & .96 & .92 \\
\hline Robust CFI & .98 & .98 & .97 & .99 & .98 & .97 \\
\hline Number of cases & 445 & 613 & 422 & 515 & 617 & 418 \\
\hline
\end{tabular}

${ }^{*} \mathrm{p}<.05 ;{ }^{* *} \mathrm{p}<.01$.

Notes: Higher values on the principle variables reflect more hawkish sentiment; therefore, $\gamma_{1}$ and $\gamma_{2}$ should be positive. Higher values on party identification reflect more democratic leanings; therefore $\gamma_{3}$ should be negative. CFA estimates omitted for clarity.

For the defense spending models:

The dependent variable is latent support for defense spending (seven-point scale). Robust standard errors are in parentheses. LM test of equal $\gamma_{1}: \chi_{2}^{2}=3.13, \mathrm{p}=.21$.

For the aid to contras models:

The dependent variable is latent support for federal spending on aid to the contras (three-point scale). Robust standard errors are in parentheses. LM test of equal $\gamma_{1}: \chi_{2}^{2}=2.59, \mathrm{p}=.27$.

and Peffley (1987) to argue that everyone can learn the political principles that animate public discourse and rely on these to the same degree to deduce policy preferences, because the information processing demands of doing so are low and because citizens possess more ability to engage in value-based reasoning than is usually recognized. The findings presented above, which are based on a comprehensive set of analyses of public opinion data that span two policy domains, five issues, five domain-specific principles, and five NES surveys, support these claims.

First, I have demonstrated that all citizens hold sensibly and comparably structured beliefs about equal opportunity, self-reliance, and limited government in the social welfare domain and militarism and anticommunism in the foreign policy domain. These findings show that the assumption that everyone holds genuine domain-specific principles is true and thereby corroborate the implicit claims made by Feldman (1988) and Hurwitz and Peffley (1987). While politically unsophisticated segments of the electorate are "innocent of ideology"
(Converse 1964), we now know that this is not the case for core beliefs and values. Second, I have shown that the politically sophisticated do not systematically rely more on these principles to constrain their policy preferences than do the unsophisticated. Generally speaking, people rely to the same degree on equal opportunity and limited government to construct attitudes toward social spending and on militarism to guide positions on defense spending and nuclear arms. Thus, with the exception of a hard issue like contra aid, political sophistication does not matter all that much. In the 13 cases of significant principle-preference links, the results unequivocally support domain-specific theory eight times (equal opportunity on needy $y_{84-86}$ and on elderly ${ }_{84-86}$, limited government on needy $y_{90}$, militarism on defense ${ }_{88-87}$ and on nuclear $\operatorname{arms}_{87}$ ); partly support sophistication-interaction theory four times (self-reliance on need $\mathrm{y}_{86}$, equality on need $y_{90}$, and militarism on contra aid $_{88-87}$ ); and are inconclusive once (equality on elderly $y_{90}$ ). In addition, the unsophisticated ground their preferences in domain-specific 


\section{TABLE 91987 Confirmatory Factor Analysis Models for Foreign Policy Principles by Level of Sophistication, Unstandardized Estimates}

\begin{tabular}{lcc}
\hline & Low & High \\
\hline Factor Loadings: & & \\
$\xi_{1}$ Militarism (five-point scale) & & \\
$\lambda_{1}$ Better way to keep peace strong military/bargaining & 1.00 & 1.00 \\
$\lambda_{2}$ How important strong military for dealing w/enemies & 0.57 & 0.81 \\
$\lambda_{3}$ U.S. maintain power even if it means brink of war & 1.87 & 0.95 \\
Cronbach's $\alpha$ & .52 & .69 \\
$\xi_{2}$ Anticommunism (five-point scale) & & \\
$\lambda_{4}$ Any time country goes communist a threat to U.S. & 1.00 & 1.00 \\
$\lambda_{5}$ U.S. do everything to prevent spread communism & 1.00 & 0.79 \\
Cronbach's $\alpha$ & .53 & .72 \\
Factor Correlation: & .68 & .74 \\
Model Fit: & & \\
Robust $\chi^{2}$ & $11.03^{*}$ & $10.82^{*}$ \\
Degrees of freedom & 4 & 4 \\
Robust $\chi^{2} /$ degrees of freedom & 2.76 & 2.71 \\
AGFI & .89 & .90 \\
Robust CFI & .91 & .97 \\
Number of cases & 186 & 159 \\
\hline
\end{tabular}

$* \mathrm{p}<.05$.

Notes: Latent and observed variables are coded so higher scores reflect more hawkish sentiment; therefore, each $\lambda_{i}$ should be positive. All factor loadings significant at $\mathrm{p}<.01$. The metric of each factor is defined by fixing the loading for the first item to 1.00. LM test of equal loadings for militarism: $\chi_{2}^{2}=4.21, \mathrm{p}=.12$. LM test of equal loadings for anticommunism: $\chi_{1}^{2}=0.50, \mathrm{p}=.48$.

principles on every issue except aid to the contras. ${ }^{8}$ Collectively, these findings rehabilitate the domainspecific theory of mass policy reasoning and suggest that the sophistication-interaction model does not apply as broadly as the conventional wisdom presumes.

This conclusion requires qualification on several fronts. First, the guns and butter issues covered here are among the most important in the American political system, but they do not exhaust the universe of issues. Clearly, more research is needed to see if the patterns observed

\footnotetext{
${ }^{8}$ The domain-specific theory posits that principles germane in one domain should not affect attitudes in unrelated domains. Such links would suggest that citizens use principles illogically and thereby undermine the theory. To see if citizens use these principles only in the relevant domains, I estimated structural models in which (1) equal opportunity and self-reliance or limited government were predictors of attitudes toward defense spending and contra aid and (2) militarism and anticommunism served as predictors of attitudes toward spending on the needy and on the elderly (party identification and ideology were included as controls in all the models). I found that principles did not affect preferences in unrelated domains in 29 of 36 tests. These analyses are available from the author upon request.
}

above hold for issues in domains such as race (i.e., affirmative action, equal treatment), civil liberties (i.e., freedom of speech, freedom of assembly), social policy (i.e., abortion, gay rights), and so on. Second, future research should pursue whether all citizens rely equally on other principles relevant to the social welfare and foreign policy domains. Does sophistication promote the use of humanitarianism when people evaluate the welfare state (Feldman and Steenbergen 2001)? Does sophistication enhance the use of cooperative internationalism when people ponder defense spending (Wittkopf 1990)? Third, the findings reported in this article rest on supporting a null hypothesis, a less than ideal research strategy. An alternative research design could seek to demonstrate that the sophisticated and the unsophisticated can be experimentally induced to ground policy preferences in broader principles to the same extent (see Lavine, Thomsen, and Gonzales 1997 for supporting evidence).

What implications do my findings have for evaluating democratic citizenship in the American public? An optimistic reading of the evidence would stress that all people base attitudes toward social spending on broader 
TABle 101987 Structural Equation Models for Foreign Policy Preferences by Level of Sophistication, Unstandardized Estimates

\begin{tabular}{|c|c|c|c|c|c|c|}
\hline & \multicolumn{2}{|c|}{ Defense Spending } & \multicolumn{2}{|c|}{ Aid to Contras } & \multicolumn{2}{|c|}{ Nuclear Weapons } \\
\hline & Low & High & Low & High & Low & High \\
\hline \multicolumn{7}{|l|}{ Structural Coefficients: } \\
\hline$\gamma_{1}$ Militarism & $\begin{array}{l}1.311^{* *} \\
(.343)\end{array}$ & $\begin{array}{l}1.066^{* *} \\
(.272)\end{array}$ & $\begin{array}{l}0.046 \\
(.190)\end{array}$ & $\begin{array}{l}0.444^{* *} \\
(.134)\end{array}$ & $\begin{array}{l}1.141^{* *} \\
(.403)\end{array}$ & $\begin{array}{l}0.833^{* *} \\
(.260)\end{array}$ \\
\hline$\gamma_{2}$ Anticommunism & $\begin{array}{r}-0.325 \\
(.389)\end{array}$ & $\begin{array}{r}-0.133 \\
(.220)\end{array}$ & $\begin{array}{l}0.041 \\
(.169)\end{array}$ & $\begin{array}{l}0.009 \\
(.117)\end{array}$ & $\begin{array}{r}-0.326 \\
(.408)\end{array}$ & $\begin{array}{r}-0.144 \\
(.230)\end{array}$ \\
\hline$\gamma_{3}$ Party identification & $\begin{array}{r}-0.074 \\
(.101)\end{array}$ & $\begin{array}{r}-0.082 \\
(.063)\end{array}$ & $\begin{array}{r}-0.048 \\
(.033)\end{array}$ & $\begin{array}{r}-0.047 \\
(.031)\end{array}$ & $\begin{array}{l}0.057 \\
(.059)\end{array}$ & $\begin{array}{r}-0.040 \\
(.065)\end{array}$ \\
\hline \multicolumn{7}{|l|}{ Model Fit: } \\
\hline Robust $\chi^{2}$ & 23.68 & 17.52 & 18.68 & 16.46 & 23.67 & 24.28 \\
\hline Degrees of freedom & 15 & 15 & 15 & 15 & 15 & 15 \\
\hline Robust $\chi^{2} /$ d.f. & 1.58 & 1.17 & 1.25 & 1.10 & 1.58 & 1.62 \\
\hline AGFI & .89 & .92 & .92 & .92 & .91 & .96 \\
\hline Robust CFI & .97 & 1.00 & .98 & 1.00 & .96 & .98 \\
\hline Number of cases & 179 & 154 & 181 & 153 & 185 & 158 \\
\hline
\end{tabular}

${ }^{*} \mathrm{p}<.05 ;{ }^{* *} \mathrm{p}<.01$.

Notes: Higher values on the principle variables reflect more hawkish sentiment; therefore, $\gamma_{1}$ and $\gamma_{2}$ should be positive. Higher values on party identification reflect more democratic leanings; therefore $\gamma_{3}$ should be negative. CFA estimates omitted for clarity.

For the defense spending models:

The dependent variable is latent attitudes toward defense spending (five-point scale). Robust standard errors are in parentheses. LM test of equal $\gamma_{1}: \chi_{1}^{2}=0.28, \mathrm{p}=60$.

For the aid to contras models:

The dependent variable is latent attitudes toward federal spending on aid to the contras (three-point scale). Robust standard errors are in parentheses. LM test of equal $\gamma_{1}: \chi_{1}^{2}=2.46, \mathrm{p}=.12$.

For the nuclear weapons models:

The dependent variable is latent support for building more nuclear weapons (five-point scale). Robust standard errors are in parentheses. LM test of equal $\gamma_{1}: \chi_{1}^{2}=0.41, \mathrm{p}=52$.

beliefs about equal opportunity and attitudes toward defense spending and nuclear weapons on beliefs about militarism. Citizens do evaluate critical issues of the day using relevant principles rather than making up positions on the spot and quickly forgetting them (Converse 1964) or haphazardly drawing upon whatever considerations happen to be temporarily accessible in their minds (Zaller 1992). A more pessimistic reading of the evidence would focus on the fact that when constructing preferences people sometimes ignore self-reliance and limited government in the social welfare arena and entirely shun anticommunism in the foreign policy domain (at least in the late 1980s). Despite the prominence these principles have assumed in American political discourse and the ease with which they could be employed to construct preferences, most people do not use them. One could conclude, quite sensibly, that mass policy reasoning is rather unsophisticated in a general sense (Luskin 2002). By grounding policy preferences in domain-specific principles the mass public meets a criterion for approximating the standards of meaningful democratic citizenship. It does not exceed this criterion by much.

\section{Appendix A \\ Question Wording and Missing Data}

For some items the question wording, format, and response options vary slightly across the surveys. The social welfare domain items, party identification, and ideology have been coded so that higher scores reflect more leftwing sentiment. The foreign policy domain items have been coded so that higher scores reflect more hawkish sentiment.

Programs for the Needy: "Should federal spending on ... be increased, decreased, or kept about the same?" 1984 and 
1986 items: food stamps, government jobs for the unemployed, and assistance to blacks. 1990 items: food stamps, programs that assist blacks, government assistance for the homeless, and child care. Three-point scales.

Programs for the Elderly: "Should federal spending on ... be increased, decreased, or kept about the same?" 1984 items: Medicare and Social Security; 1986 and 1990 item: Social Security. Three-point scales.

Equal Opportunity: (1) "Our society should do whatever is necessary to make sure that everyone has an equal opportunity to succeed." (2) "One of the big problems in this country is that we don't give everyone an equal chance." (3) "If people were treated more equally in this country, we would have many fewer problems." Five-point agree/disagree scales.

Self-Reliance: (1) “Most people who don't get ahead should not blame the system; they have only themselves to blame." (2) "Hard work offers little guarantee of success." (3) "If people work hard they almost always get what they want." (4) "Any person who is willing to work hard has a good chance of succeeding." Five-point agree/disagree scales.

Limited Government: (1) "One, the less government the better; or two, there are more things the government should be doing." (2) "One, we need a strong government to handle today's complex economic problems; or two, the free market can handle these problems without government being involved." (3) "One, the main reason government has become bigger over the years is because it has gotten involved in things that people should do for themselves; or two, government has become bigger because the problems we face today have become bigger." Three-point scales (includes volunteered middle option).

Party Identification: Two measures are used. The first taps social identity with a party; the second taps the affective nature of that identification. (1) "Generally speaking, do you usually think of yourself as a Republican, a Democrat, an independent, or what?" [Partisan probe] "Would you call yourself a strong... or a not very strong...?" [Nonpartisan probe] "Do you think of yourself as closer to the Republican party or the Democratic party?" Sevenpoint scale. (2) (Democratic Party feeling thermometer Republican Party feeling thermometer +100$) / 25$. Eightpoint scale. Minor party identifiers/apoliticals on (1) and can't rate responses on (2) recoded to scale midpoints to preserve cases.

Ideology: Measured with the self-identification item and the follow up probe for people who initially answer don't know/haven't thought much (this greatly reduces missing data). "We hear a lot of talk these days about liberals and conservatives. Here is a seven-point scale on which the political views that people hold are arranged from extremely liberal to extremely conservative. Where would you place yourself on this scale, or haven't you thought much about this?" [Probe] "If you had to choose, would you consider yourself a liberal or a conservative?" Three-point scale.

Defense Spending: "Some people believe that we should spend much less money for defense. Others feel that defense spending should be greatly increased. Where would you place yourself on this scale, or haven't you thought much about this?" Seven-point scale for 1988 and fivepoint scale for 1987.

Aid to Contras: "Should federal spending on aid to the contras in Nicaragua be increased, decreased, or kept about the same." Three-point scale.

Nuclear Weapons: "Would you strongly favor, not so strongly favor, not so strongly oppose, or strongly oppose the U.S. building more nuclear weapons?" Five-point scale.

Militarism: (1) "Which do you think is the better way for us to keep peace-by having a very strong military so other countries won't attack us, or by working out our disagreements at the bargaining table?" (2) "How important is it for the U.S. to have a strong military force in order to be effective in dealing with our enemies? Is it extremely important, very important, somewhat important, or not at all important?" (3) "The U.S. should maintain its position as the world's most powerful nation even if it means going to the brink of war." Three- to five-point scales.

Anticommunism: (1) "Any time a country goes communist, it should be considered a threat to the vital interests and security of the United States." (2) "The United States should do everything it can to prevent the spread of communism to any other part of the world." Five-point scales.

Political Sophistication: The sophistication measure is a simple additive scale indicating the number of correct answers given to 14 or 15 knowledge items. Mondak (2001) shows that such items are systematically biased by a guessing response set (i.e., guessers receive higher scores than nonguessers). To reduce this bias I adopt his recommended post hoc correction procedure for the multiplechoice items. This procedure is not utilized for the openended job/office holder items because some of these are too easy or too hard to assume a 50-50 chance of guessing 
correctly. These items are retained because their discriminatory power varies widely. 1984 items: correct placements for Reagan, Mondale, and the Democratic and Republican parties on ideology; correct placements for the parties on government spending, defense spending, and Central America involvement; and pre/post-election party control of the House and Senate. 1986 and 1987 items: correct placements for both parties on ideology, government spending, and defense spending; party control of the House and Senate; and Bush, Weinberger, Rehnquist, Volker, Dole, and O'Neill jobs. 1988 items: party placements and House and Senate control like the 1986 and 1987 items and Kennedy, Schultz, Rehnquist, Gorbachev, Thatcher, and Arafat jobs. 1990 items: party placements and House and Senate control like the 1986 and 1987 items and Quayle, Mitchell, Rehnquist, Gorbachev, Thatcher, Mandela, and Foley jobs.

I do not believe that missing data represent a serious problem for the analyses in this article, and where it may be problematic I have performed diagnostics to guard against the possibility of drawing mistaken inferences. Note first that the average missing data rates for the items are fairly to very low (excluding ideology, which has a rate of $11 \%$ ). The rate is less than one percent for five of the six domainspecific principles and less than $3 \%$ for the sixth. The rates are less than 5 and $2.5 \%$ for the needy and elderly items, respectively. For foreign policy preferences the average rates are about 7,6 , and $0 \%$ for defense spending, contra aid, and nuclear weapons, respectively.

Given the very low missing data rates on the domainspecific principle items, missing data are not much of a problem for the confirmatory factor analysis estimates in Tables 1, 3, 5, 7, and 9. Similarly, given the low missingdata rates for the single-item dependent variables and the exclusion of ideology in the foreign policy models, missing data are unlikely to be a serious problem for the structural equation estimates in Tables 8 and 10. In contrast, missing data on ideology and the multi-item spending measures reduces the sample sizes in some of the structural equation models in Tables 2, 4, and 6 by nontrivial amounts, especially among the unsophisticated. To gauge the robustness of my results, I reestimated these models using each single item as a measure of social spending wherever possible (i.e., needy ${ }_{84-86-90}$ and elderly ${ }_{84}$ ), which is justified because the items tap the same underlying construct (see Appendix B), and without ideology, which is justified because this variable has very little impact on spending preferences (see Tables 2,4 , and 6). The results from these models do not differ in any significant way from those reported in the text. All of these results are available from the author upon request.

\section{Appendix B}

1984 Confirmatory Factor Analysis Models for Social Welfare Spending Preferences by Level of Sophistication, Unstandardized Estimates

\begin{tabular}{|c|c|c|c|}
\hline & Low & Medium & High \\
\hline \multicolumn{4}{|l|}{ Factor Loadings: } \\
\hline \multicolumn{4}{|c|}{$\xi_{1}$ Programs for the needy (three-point scale) } \\
\hline$\lambda_{1}$ Food stamps & 1.00 & 1.00 & 1.00 \\
\hline $\begin{array}{l}\lambda_{2} \text { Government jobs } \\
\text { for the unemployed }\end{array}$ & 0.81 & 0.78 & 0.93 \\
\hline$\lambda_{3}$ Assistance to blacks & 0.82 & 0.80 & 0.83 \\
\hline Cronbach's $\alpha$ & .65 & .68 & .70 \\
\hline \multicolumn{4}{|c|}{$\xi_{2}$ Programs for the elderly (three-point scale) } \\
\hline$\lambda_{4}$ Medicare & 1.00 & 1.00 & 1.00 \\
\hline$\lambda_{5}$ Social Security & 0.77 & 0.98 & 0.81 \\
\hline Cronbach's $\alpha$ & .63 & .63 & .70 \\
\hline Factor Correlation: & .70 & .68 & .74 \\
\hline \multicolumn{4}{|l|}{ Model Fit: } \\
\hline Robust $\chi^{2}$ & $15.01^{* *}$ & $18.36^{* *}$ & 5.58 \\
\hline Degrees of freedom & 4 & 4 & 4 \\
\hline $\begin{array}{l}\text { Robust } \chi^{2} / \text { degrees } \\
\text { of freedom }\end{array}$ & 3.75 & 4.59 & 1.40 \\
\hline AGFI & .96 & .95 & .98 \\
\hline Robust CFI & .98 & .97 & 1.00 \\
\hline Number of cases & 594 & 586 & 503 \\
\hline
\end{tabular}

${ }^{* *} \mathrm{p}<.01$.

Notes: Latent and observed variables are coded so higher scores reflect more prospending sentiment; therefore, each $\lambda_{i}$ should be positive. All factor loadings significant at $\mathrm{p}<.01$. The metric of each factor is defined by fixing the loading for the first item to 1.00. LM test of equal loadings for programs for the needy: $\chi_{4}^{2}=$ $1.63, \mathrm{p}=.80$. LM test of equal loadings for programs for the elderly: $\chi_{2}^{2}=2.40, \mathrm{p}=.30$.

\section{References}

Achen, Christopher H. 1983. "Towards Theories of Data: The State of Political Methodology." In Political Science: The State of the Discipline, ed. Ada W. Finifter. Washington: American Political Science Association, pp. 69-93.

Bentler, Peter M. 1995. EQS: Structural Equations Program Manual. Encino, CA: Multivariate Software.

Bollen, Kenneth A. 1989. Structural Equation Models with Latent Variables. New York: Wiley.

Chong, Dennis, Herbert McClosky, and John Zaller. 1983. "Patterns of Support for Democratic and Capitalist Values." British Journal of Political Science 13(4):401-40.

Chou, Chin-Ping, and Peter M. Bentler. 1995. "Estimates and Tests in Structural Equation Modeling." In Structural 
Equation Modeling: Concepts, Issues, and Applications, ed. Rick H. Hoyle. Thousand Oaks: Sage Publications, pp. 37-55.

Converse, Philip E. 1964. "The Nature of Belief Systems in Mass Publics." In Ideology and Discontent, ed. David Apter. New York: Free Press, pp. 206-61.

Curran, Patrick J., Stephen G. West, and John F. Finch. 1996. "The Robustness of Test Statistics to Nonnormality and Specification Error in Confirmatory Factor Analysis." Psychological Methods 1(1):16-29.

Delli Carpini, Michael X., and Scott Keeter. 1996. What Americans Know About Politics and Why It Matters. New Haven: Yale University Press.

Drasgow, Fritz, and Ruth Kanfer. 1985. "Equivalence of Psychological Measurement in Heterogeneous Populations." Journal of Applied Psychology 70(4):662-80.

Feldman, Stanley. 1988. "Structure and Consistency in Public Opinion: The Role of Core Beliefs and Values." American Journal of Political Science 32(2):416-40.

Feldman, Stanley, and Marco R. Steenbergen. 2001. "The Humanitarian Foundation of Public Support for Social Welfare. American Journal of Political Science 45(3):658-77.

Feldman, Stanley, and John Zaller. 1992. "The Political Culture of Ambivalence: Ideological Responses to the Welfare State.” American Journal of Political Science 36(1):268-307.

Goren, Paul. 2001. "Core Principles and Policy Reasoning in Mass Publics: A Test of Two Theories." British Journal of Political Science 31(1):159-77.

Hu, Li-Tze, and Peter M. Bentler. 1995. "Evaluating Model Fit." In Structural Equation Modeling: Concepts, Issues, and Applications, ed. Rick H. Hoyle. Thousand Oaks: Sage Publications, pp. 76-99.

Hurwitz, Jon, and Mark Peffley. 1990. "Public Images of the Soviet Union: The Impact on Foreign Policy Attitudes.” Journal of Politics 52(1):3-28.
Hurwitz, Jon, and Mark Peffley. 1987. "How are Foreign Policy Attitudes Structured? A Hierarchical Model." American Political Science Review 81(4):1099-1120.

Kinder, Donald R., and Lynn M. Sanders. 1996. Divided by Color. Chicago: University of Chicago Press.

Lavine, Howard, Cynthia J. Thomsen, and Marti HopeGonzales. 1997. "The Development of Interattitudinal Consistency: The Shared Consequences Model." Journal of Personality and Social Psychology 72(4):735-49.

Luskin, Robert C. 2002. "Political Psychology, Political Behavior, and Politics: Questions of Aggregation, Causal Distance, and Taste." In Thinking About Political Psychology, ed. James H. Kuklinski. New York: Cambridge University Press, pp. 21750 .

Mondak, Jeffery J. 2001. "Developing Valid Knowledge Scales." American Journal of Political Science 45(1):224-38.

Reise, Steven P., Keith Widaman, and Robin H. Pugh. 1993. "Confirmatory Factor Analysis and Item Response Theory: Two Approaches for Exploring Measurement Equivalence." Psychological Bulletin 114(3):552-66.

Sears, David O, P. J. Henry, and Rick Kosterman. 2000. "Egalitarian Values and Contemporary Racial Politics." In Racialized Politics, ed. David O. Sears, Jim Sidanius, and Lawrence Bobo. Chicago: University of Chicago Press, pp. 75-117.

Sniderman, Paul M., Richard A. Brody, and Philip E. Tetlock. 1991. Reasoning and Choice. New York: Cambridge University Press.

Wheaton, Blair, Bengt Muthen, Duane F. Alwin, and Gene F. Summers. 1977. "Assessing Reliability and Stability in Panel Models.” Sociological Methodology 8:84-136.

Wittkopf, Eugene. 1990. Faces of Internationalism. Durham: Duke University Press.

Zaller, John R. 1992. The Nature and Origins of Mass Opinion. New York: Cambridge University Press. 